\title{
Impact of $A P O E$ gene polymorphisms on the lipid profile in an Algerian population
}

\author{
Houssam Boulenouar ${ }^{1}$, Sounnia Mediene Benchekor ${ }^{1,2}$, Djabaria Naïma Meroufel', Sarah Aicha Lardjam Hetraf', \\ Hadjira Ouhaibi Djellouli ${ }^{1,2}$, Xavier Hermant ${ }^{3}$, Benjamin Grenier-Boley ${ }^{3}$, Imane Hamani Medjaoui ${ }^{4}$, \\ Nadhira Saidi Mehtar ${ }^{1}$, Philippe Amouyel ${ }^{3}$, Leila Houti ${ }^{1,5,6}$, Aline Meirhaeghe ${ }^{3}$ and Louisa Goumidi ${ }^{3^{*}}$
}

\begin{abstract}
Background: The importance of apolipoprotein E (APOE) in lipid and lipoprotein metabolism is well established. However, the impact of APOE polymorphisms has never been investigated in an Algerian population. This study assessed, for the fist time, the relationships between three APOE polymorphisms (epsilon, rs439401, rs4420638) and plasma lipid concentrations in a general population sample from Algeria.

Methods: The association analysis was performed in the ISOR study, a representative sample of the population living in Oran (787 subjects aged between 30 and 64). Polymorphisms were considered both individually and as haplotypes.

Results: In the ISOR sample, APOE \&4 allele carriers had higher plasma triglyceride ( $p=0.0002$ ), total cholesterol $(p=0.009)$ and LDL-cholesterol ( $p=0.003$ ) levels than $\varepsilon 3$ allele carriers. No significant associations were detected for the rs4420638 and rs439401 SNPs. Linkage disequilibrium and haplotype analyses confirmed the respectively deleterious and protective impacts of the $\varepsilon 4$ and $\varepsilon 2$ alleles on LDL-cholesterol levels and showed that the $\mathrm{G}$ allele of the rs4420638 polymorphism may exert a protective effect on LDL-cholesterol levels in subjects bearing the APOE epsilon 4 allele.

Conclusion: Our results showed that (i) the APOE epsilon polymorphism has the expected impact on the plasma lipid profile and (ii) the rs $4420638 \mathrm{G}$ allele may counterbalance the deleterious effect of the $\varepsilon 4$ allele on LDL-cholesterol levels in an Algerian population.
\end{abstract}

Keywords: APOE, Polymorphism, Algerian population, Lipid parameters, Cardiovascular risk, General population sample, North Africa

\section{Background}

Dyslipidemia (defined by elevated levels of fasting and post-prandial plasma triglyceride-rich lipoproteins, abnormally low high-density lipoprotein (HDL) levels and elevated low-density lipoprotein (LDL) concentrations) is associated with atherosclerosis and coronary heart disease (CHD) [1,2]. Coronary artery disease is a major cause of morbidity and mortality in both industrialized countries and developing countries, such as Algeria [3,4]. It has been estimated that there were 7.3 million deaths worldwide from ischemic heart disease in 2008 (12.4\% of

\footnotetext{
* Correspondence: louisa.goumidi@pasteur-lille.fr

${ }^{3}$ INSERM, U744; Institut Pasteur de Lille, Université Lille Nord de France, Lille, France

Full list of author information is available at the end of the article
}

all mortality). Furthermore, it is predicted that CHD will still be the leading cause of death in 2020 [5,6].

Commonly studied intermediate traits associated with CHD include plasma levels of cholesterol (total cholesterol, LDL-cholesterol and HDL-cholesterol), body mass index (BMI) and blood pressure. These traits are influenced by a combination of genetic [7] and environmental factors (such as diet, alcohol and physical activity) [8-10].

The results of several meta-analyses have firmly established that the apolipoprotein E (APOE) epsilon polymorphism (defined by the rs7412 and rs429358 single nucleotide polymorphisms (SNPs)) is a genetic risk factor for CHD [11-14]. Indeed, APOE has an important role in the metabolism of lipoproteins and is a ligand for LDL-cholesterol and APOE receptors [15]. The epsilon
C Biomed Central

(c) 2013 Boulenouar et al.; licensee BioMed Central Ltd. This is an open access article distributed under the terms of the Creative Commons Attribution License (http://creativecommons.org/licenses/by/2.0), which permits unrestricted use, distribution, and reproduction in any medium, provided the original work is properly cited. 
polymorphism in the $A P O E$ gene leads to the generation of APOE2, APOE3 and APOE4 isoforms, which are coded by three codominant alleles (designated as $\varepsilon 2, \varepsilon 3$ and $\varepsilon 4$ ). The three isoforms differ by an amino acid substitution at position 112 or position 158 in the 299amino-acid peptide chain [16]. The isoforms interact differently with specific lipoprotein receptors and thus influence plasma cholesterol concentrations [17]. The $A P O E$ \&4 allele is associated with higher total and LDLcholesterol levels and a higher risk of CHD, whereas the $A P O E \varepsilon 2$ allele is associated with the opposite (i.e. protective) effects in Caucasian populations [18-21].

Furthermore, two other $A P O E$ polymorphisms have been found to display associations with various metabolic traits. Firstly, the rs439401 SNP was associated with higher plasma triglyceride and lower plasma HDL-cholesterol concentrations in a meta-analysis of genome-wide association studies (GWAS) in 16 European cohorts [22]. Secondly, the rs4420638 SNP is reportedly associated with lower plasma HDL-cholesterol levels, higher total cholesterol and LDL-cholesterol levels and higher total cholesterol/HDL-cholesterol and LDL-cholesterol/HDLcholesterol ratios [14,23-25].

Very few studies have investigated putative associations between the APOE epsilon polymorphism and plasma lipid levels in North African populations. Indeed, only two studies (in Moroccan and Tunisian populations) reported that the $A P O E$ \&4 allele is associated with higher plasma concentrations of total cholesterol and LDL-cholesterol, whereas the $A P O E \varepsilon 2$ allele shows the opposite association [26-28]. However, no data for the rs439401 and rs4420638 polymorphisms in these populations are available.

To the best of our knowledge, the relationship between $A P O E$ polymorphisms and plasma lipid and lipoprotein concentrations in an Algerian population has never previously been studied. We therefore decided to assess the relationships between $A P O E$ epsilon, rs439401 and rs4420638 polymorphisms and plasma lipid concentrations in a population sample from the city of Oran in north-west Algeria, the ISOR study.

\section{Results}

\section{Genotype and allele distributions}

The allele and genotype distributions of the $A P O E$ polymorphisms are presented in Table 1. There was no evidence of significant deviation from Hardy-Weinberg equilibrium in any distributions.

\section{Linkage disequilibrium}

We evaluated the linkage disequilibrium (LD) between the APOE epsilon (rs429358 and rs7412), rs439401 and rs4420638 polymorphisms (Figure 1). The rs439401 and rs4420638 SNPs were not in LD with the APOE epsilon
Table 1 Genotype distributions of the APOE polymorphisms in the ISOR study

\begin{tabular}{|c|c|c|c|}
\hline Polymorphism & & $n$ & (\%) \\
\hline \multirow[t]{13}{*}{ Epsilon } & Genotype & & \\
\hline & $\varepsilon 2 / \varepsilon 2$ & 3 & $(0.4)$ \\
\hline & $\varepsilon 2 / \varepsilon 3$ & 64 & $(8.7)$ \\
\hline & $\varepsilon 2 / \varepsilon 4$ & 3 & $(0.4)$ \\
\hline & ع3/ع3 & 525 & (71.8) \\
\hline & $\varepsilon 3 / \varepsilon 4$ & 124 & (16.9) \\
\hline & $\varepsilon 4 / \varepsilon 4$ & 13 & (1.8) \\
\hline & Total & 732 & \\
\hline & $\mathrm{pH}-\mathrm{W}$ & 0.07 & \\
\hline & Allele & & \\
\hline & $\varepsilon 2$ & 73 & (5.0) \\
\hline & $\varepsilon 3$ & 1238 & (84.6) \\
\hline & $\varepsilon 4$ & 153 & $(10.4)$ \\
\hline \multirow[t]{9}{*}{ rs439401 } & Genotype & & \\
\hline & $\mathrm{CC}$ & 288 & (39.0) \\
\hline & $\mathrm{CT}$ & 335 & $(45.4)$ \\
\hline & $\pi$ & 115 & (15.6) \\
\hline & Total & 738 & \\
\hline & $\mathrm{pH}-\mathrm{W}$ & 0.28 & \\
\hline & Allele & & \\
\hline & C & 911 & $(61.7)$ \\
\hline & T & 565 & (38.3) \\
\hline \multirow[t]{9}{*}{ rs4420638 } & Genotype & & \\
\hline & $\mathrm{AA}$ & 596 & (78.9) \\
\hline & $A G$ & 149 & (19.8) \\
\hline & GG & 10 & (1.3) \\
\hline & Total & 755 & \\
\hline & $\mathrm{pH}-\mathrm{W}$ & 0.84 & \\
\hline & Allele & & \\
\hline & A & 1341 & (88.8) \\
\hline & G & 169 & $(11.2)$ \\
\hline
\end{tabular}

H-W: Hardy-Weinberg equilibrium.

polymorphism $\left(\mathrm{r}^{2}<0.16\right)$. So the analysis of all polymorphisms was investigated.

\section{Association studies}

The various associations between the three APOE polymorphisms and the anthropometric phenotypes (weight, waist and hip circumferences and BMI), biochemical phenotypes (glucose, insulin, fasting plasma triglyceride, total cholesterol, HDL-cholesterol and LDL-cholesterol levels) and clinical phenotypes (SBP and DBP) were assessed (Tables 2-3). 


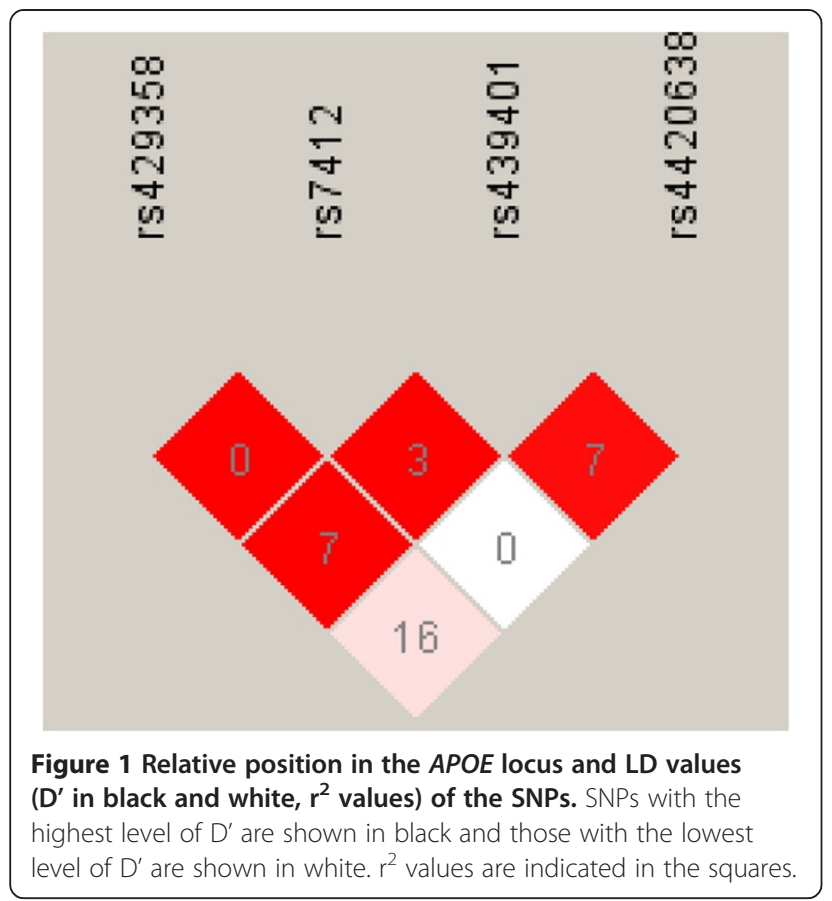

Table 2 Association between the APOE epsilon polymorphism and anthropometric, biochemical and clinical parameters in the ISOR study

\begin{tabular}{|c|c|c|c|c|c|}
\hline & $\varepsilon 2 \varepsilon 2+\varepsilon 2 \varepsilon 3$ & $\varepsilon 3 \varepsilon 3$ & $\varepsilon 3 \varepsilon 4+\varepsilon 4 \varepsilon 4$ & $p^{a}$ & $p^{b}$ \\
\hline$n$ & 67 & 522 & 137 & & \\
\hline Weight (kg) & $74.6 \pm 17.9$ & $71.0 \pm 14.2$ & $70.7 \pm 13.6$ & 0.05 & 0.6 \\
\hline Waist (cm) & $89.4 \pm 13.3$ & $87.6 \pm 12.5$ & $87.4 \pm 11.6$ & 0.33 & 0.81 \\
\hline Hip (cm) & $103.0 \pm 10.6$ & $101.9 \pm 9.7$ & $101.0 \pm 9.3$ & 0.16 & 0.6 \\
\hline BMI $\left(\mathrm{kg} / \mathrm{m}^{2}\right)$ & $27.3 \pm 6.2$ & $26.1 \pm 5.1$ & $25.5 \pm 4.5$ & 0.02 & 0.42 \\
\hline Waist-to-hip ratio & $0.87 \pm 0.08$ & $0.86 \pm 0.09$ & $0.87 \pm 0.08$ & 0.93 & 0.71 \\
\hline Fasting glucose $(\mathrm{mmol} / \mathrm{L})^{*}$ & $4.98 \pm 1.28$ & $5.04 \pm 1.30$ & $5.20 \pm 1.53$ & 0.23 & 0.25 \\
\hline Fasting insulin $(\mu \mathrm{l} U / \mathrm{mL})^{*}$ & $9.18 \pm 6.65$ & $7.95 \pm 5.48$ & $8.65 \pm 8.31$ & 0.76 & 0.35 \\
\hline Triglycerides $(\mathrm{mmol} / \mathrm{L})^{\dagger}$ & $1.34 \pm 0.78$ & $1.09 \pm 0.44$ & $1.24 \pm 0.48$ & 0.10 & 0.0002 \\
\hline Total cholesterol $(\mathrm{mmol} / \mathrm{L})^{\dagger}$ & $4.25 \pm 0.95$ & $4.41 \pm 0.86$ & $4.63 \pm 1.11$ & 0.10 & 0.009 \\
\hline HDL-cholesterol $(\mathrm{mmol} / \mathrm{L})^{\dagger}$ & $1.27 \pm 0.34$ & $1.26 \pm 0.30$ & $1.22 \pm 0.32$ & 0.40 & 0.06 \\
\hline LDL-cholesterol $(\mathrm{mmol} / \mathrm{L})^{\dagger}$ & $2.47 \pm 0.85$ & $2.64 \pm 0.82$ & $2.88 \pm 1.05$ & 0.06 & 0.003 \\
\hline LDL-cholesterol/HDL-cholesterol ratio ${ }^{\dagger}$ & $2.14 \pm 1.07$ & $2.25 \pm 1.00$ & $2.55 \pm 1.23$ & 0.18 & 0.001 \\
\hline $\mathrm{SBP}(\mathrm{mmHg})^{\dagger \dagger}$ & $122.6 \pm 16.3$ & $120.6 \pm 14.8$ & $122.7 \pm 17.8$ & 0.95 & 0.13 \\
\hline $\mathrm{DBP}(\mathrm{mmHg})^{+\dagger}$ & $75.5 \pm 8.8$ & $76.6 \pm 9.8$ & $76.3 \pm 11.1$ & 0.83 & 0.38 \\
\hline
\end{tabular}

Data are expressed as the mean \pm SD. SBP: systolic blood pressure; DBP: diastolic blood pressure.

$\mathrm{p}$ values were adjusted for age, gender, smoking status and physical activity for anthropometric variables.

$\mathrm{p}$ values were adjusted for age, gender, BMI, smoking status and physical activity for biological and biochemical variables.

$p^{a}$ : p values obtained when comparing $\varepsilon 2 \varepsilon 2+\varepsilon 2 \varepsilon 3$ subjects with $\varepsilon 3 \varepsilon 3$ subjects.

$p^{b}: p$ values obtained when comparing $\varepsilon 3 \varepsilon 4+\varepsilon 4 \varepsilon 4$ subjects with $\varepsilon 3 \varepsilon 3$ subjects.

*subjects treated for diabetes were excluded $(n=54)$.

${ }^{\dagger}$ subjects treated with lipid-lowering drugs were excluded $(n=36)$.

${ }^{+\dagger}$ subjects treated for hypertension were excluded $(n=89)$. ciations between the $A P O E$ polymorphisms and plasma lipids, in men and women separately and in the nonmenopausal women group. All previously described associations were replicated in each group, meaning that gender
As gender, menopausal status in women and lipid-lowering
drugs use may significantly impact plasma lipid levels, we

As gender, menopausal status in women and lipid-lowering
drugs use may significantly impact plasma lipid levels, we took into account these confounders and investigated asso-

The APOE epsilon polymorphism In contrast, $\varepsilon 4$ allele carriers had significantly higher levels and LDL-cholesterol/HDL-cholesterol ratio $(p=0.001)$

The rs4420638 and rs439401 polymorphisms

No significant associations were detected for the rs4420638 rs439401 was significantly associated with lower plasma triglyceride levels $(p=0.005)$ (Table 3$)$. This association disappeared after further adjustment for the $A P O E$ epsilon polymorphism $(p=0.25)$.

\section{Gene-environment analyses} (n) 
Table 3 Association between the APOE rs439401 and rs4420638 SNPs and anthropometric, biochemical and clinical parameters in the ISOR study

\begin{tabular}{|c|c|c|c|c|c|c|c|c|c|c|}
\hline & \multicolumn{5}{|c|}{ rs439401 } & \multicolumn{5}{|c|}{ rs4420638 } \\
\hline & $\mathrm{CC}$ & CT & TT & $p^{1}$ & $p^{2}$ & AA & AG & GG & $p^{1}$ & $p^{2}$ \\
\hline$n$ & 288 & 335 & 115 & & & 596 & 149 & 10 & & \\
\hline Weight (kg) & $71.6 \pm 14.5$ & $71.5 \pm 15.0$ & $70.8 \pm 13.6$ & 0.87 & 0.68 & $71.7 \pm 14.9$ & $69.4 \pm 13.4$ & $67.7 \pm 5.9$ & 0.04 & 0.04 \\
\hline Waist (cm) & $88.1 \pm 12.6$ & $87.7 \pm 12.2$ & $87.4 \pm 12.4$ & 0.83 & 0.66 & $88.0 \pm 12.5$ & $86.7 \pm 11.9$ & $83.5 \pm 11.2$ & 0.11 & 0.07 \\
\hline Hip (cm) & $102.2 \pm 10.0$ & $102.0 \pm 10.00$ & $101.3 \pm 9.1$ & 0.56 & 0.45 & $102.2 \pm 9.9$ & $100.8 \pm 9.3$ & $97.0 \pm 6.2$ & 0.04 & 0.04 \\
\hline BMI $\left(\mathrm{kg} / \mathrm{m}^{2}\right)$ & $26.0 \pm 5.2$ & $26.3 \pm 5.1$ & $26.0 \pm 4.9$ & 0.65 & 0.79 & $26.2 \pm 5.2$ & $25.4 \pm 4.6$ & $24.5 \pm 2.9$ & 0.05 & 0.08 \\
\hline Waist-to-hip ratio & $0.86 \pm 0.08$ & $0.86 \pm 0.10$ & $0.86 \pm 0.08$ & 0.83 & 0.92 & $0.86 \pm 0.08$ & $0.86 \pm 0.11$ & $0.86 \pm 0.11$ & 0.99 & 0.6 \\
\hline Fasting glucose $(\mathrm{mmol} / \mathrm{L})^{*}$ & $5.04 \pm 1.20$ & $5.10 \pm 1.52$ & $5.06 \pm 1.14$ & 0.69 & 0.48 & $5.03 \pm 1.26$ & $5.20 \pm 1.60$ & $5.03 \pm 0.70$ & 0.18 & 0.3 \\
\hline Fasting insulin $(\mu \mathrm{lU} / \mathrm{mL})^{*}$ & $8.02 \pm 6.09$ & $8.57 \pm 6.53$ & $7.58 \pm 5.62$ & 0.72 & 0.7 & $8.07 \pm 5.62$ & $8.75 \pm 8.28$ & $6.61 \pm 2.89$ & 0.31 & 0.58 \\
\hline Triglycerides $(\mathrm{mmol} / \mathrm{L})^{\dagger}$ & $1.20 \pm 0.51$ & $1.14 \pm 0.50$ & $1.07 \pm 0.47$ & 0.005 & 0.25 & $1.14 \pm 0.49$ & $1.19 \pm 0.55$ & $1.21 \pm 0.41$ & 0.06 & 0.8 \\
\hline Total cholesterol $(\mathrm{mmol} / \mathrm{L})^{\dagger}$ & $4.50 \pm 1.02$ & $4.42 \pm 0.86$ & $4.35 \pm 0.82$ & 0.14 & 0.42 & $4.44 \pm 0.90$ & $4.43 \pm 0.98$ & $4.51 \pm 1.02$ & 0.76 & 0.42 \\
\hline $\mathrm{HDL}$-cholesterol $(\mathrm{mmol} / \mathrm{L})^{\dagger}$ & $1.24 \pm 0.31$ & $1.26 \pm 0.33$ & $1.27 \pm 0.27$ & 0.29 & 0.41 & $1.25 \pm 0.30$ & $1.27 \pm 0.34$ & $1.17 \pm 0.24$ & 0.82 & 0.5 \\
\hline LDL-cholesterol $(\mathrm{mmol} / \mathrm{L})^{\dagger}$ & $2.74 \pm 0.97$ & $2.66 \pm 0.82$ & $2.58 \pm 0.82$ & 0.11 & 0.31 & $2.69 \pm 0.87$ & $2.64 \pm 0.88$ & $2.78 \pm 0.88$ & 0.94 & 0.20 \\
\hline LDL-cholesterol/HDL-cholesterol ratio $^{\dagger}$ & $2.39 \pm 1.15$ & $2.38 \pm 2.12$ & $2.17 \pm 0.88$ & 0.31 & 0.19 & $2.37 \pm 1.76$ & $2.25 \pm 1.02$ & $2.36 \pm 0.52$ & 0.65 & 0.09 \\
\hline $\mathrm{SBP}(\mathrm{mmHg})^{\dagger \dagger}$ & $121.4 \pm 16.4$ & $120.9 \pm 14.8$ & $121.1 \pm 15.1$ & 0.66 & 0.44 & $120.9 \pm 14.8$ & $121.0 \pm 17.6$ & $128.1 \pm 18.9$ & 0.36 & 0.51 \\
\hline $\mathrm{DBP}(\mathrm{mmHg})^{\dagger+}$ & $75.4 \pm 10.1$ & $75.9 \pm 8.7$ & $76.4 \pm 8.6$ & 0.14 & 0.09 & $75.7 \pm 9.0$ & $75.7 \pm 10.1$ & $78.1 \pm 12.2$ & 0.56 & 0.58 \\
\hline
\end{tabular}

Data are expressed as the mean \pm SD. SBP: systolic blood pressure, DBP: diastolic blood pressure.

$p^{\prime}$ : $\mathrm{p}$ values were adjusted for age, gender, smoking status and physical activity for anthropometric variables. $\mathrm{p}$ values were adjusted for age, gender, BMI, smoking status and physical activity for biological and biochemical variables.

$p^{2}$ : as above and additionally for $A P O E$ epsilon status.

*subjects treated for diabetes were excluded $(n=54)$.

t subjects treated with lipid-lowering drugs were excluded $(n=36)$

${ }^{+t}$ subjects treated for hypertension were excluded $(n=89)$.

and menopausal status had no notable influence on the present associations (data not shown).

\section{Haplotype analysis}

We explored the haplotype effects of the APOE epsilon (rs429358 and rs7412) and the rs439401 and rs4420638 SNPs on plasma LDL-cholesterol levels. First, we selected the most informative haplotype configuration. The best haplotype model included the APOE epsilon and the rs 4420638 polymorphisms ( $p=0.002$, with 4 d.f.). We then performed haplotype analysis (using Thesias [29]) for the $A P O E$ epsilon and rs4420638. Five haplotypes were inferred ( $\varepsilon 3 \mathrm{~A}, \varepsilon 3 \mathrm{G}, \varepsilon 4 \mathrm{~A}, \varepsilon 4 \mathrm{G}$ and $\varepsilon 2 \mathrm{~A}$ ) (Table 4). The test for an overall haplotype effect was significant $(p=0.002)$.
When compared with the most frequent (reference) $\varepsilon 3 \mathrm{~A}$ haplotype, the $\varepsilon 4 \mathrm{~A}$ haplotype was associated with higher LDL-cholesterol levels $(\Delta[95 \% \mathrm{CI}]=+0.35[0.18-0.51]$ $\mathrm{mmol} / \mathrm{L}, p=0.0001)$, whereas the $\varepsilon 2 \mathrm{~A}$ haplotype was associated with lower LDL-cholesterol levels $(\Delta[95 \% \mathrm{CI}]=-0.20$ $[-0.41--0.01] \mathrm{mmol} / \mathrm{L}, p=0.05)$, confirming the respectively deleterious and protective impacts of the $\varepsilon 4$ and $\varepsilon 2$ alleles. The $83 G$ haplotype was associated with similar LDL-cholesterol levels $(\Delta[95 \%$ confidence interval $(\mathrm{CI})]=0.02[-0.17-+0.21] \mathrm{mmol} / \mathrm{L}, p=0.74)$ compared with carriers of the $\varepsilon 3 \mathrm{~A}$ haplotype; this result suggests that the rs4420638 $\mathrm{G}$ allele does not have an effect in an $\varepsilon 3$ background. Interestingly and contrarily to what we observed for the $\varepsilon 4 \mathrm{~A}$ haplotype, the $\varepsilon 4 \mathrm{G}$ haplotype was not associated with higher LDL-cholesterol levels, relative to

Table 4 Effect of the APOE haplotypes on plasma LDL-cholesterol levels in the ISOR study

\begin{tabular}{|c|c|c|c|c|}
\hline \multicolumn{2}{|c|}{ Haplotypes } & \multirow[b]{2}{*}{ Frequency } & \multirow[b]{2}{*}{ Haplotype effect $[95 \% \mathrm{Cl}](\mathrm{mmol} / \mathrm{L})$} & \multirow[b]{2}{*}{$p$} \\
\hline rs429358/rs7412/rs4420638 & $\varepsilon / r s 4420638$ & & & \\
\hline TCA & $\varepsilon 3 \mathrm{~A}$ & 0.784 & reference & - \\
\hline TCG & $\varepsilon 3 G$ & 0.061 & $0.02[-0.17-0.21]$ & 0.74 \\
\hline CCA & $\varepsilon 4 \mathrm{~A}$ & 0.054 & $0.35[0.18-0.51]$ & 0.0001 \\
\hline CCG & $\varepsilon 4 \mathrm{G}$ & 0.051 & $-0.05[-0.27-0.17]$ & 0.81 \\
\hline TTA & $\varepsilon 2 \mathrm{~A}$ & 0.050 & $-0.20[-0.41--0.01]$ & 0.05 \\
\hline
\end{tabular}

Polymorphisms are ordered according to their position in the genomic sequence.

Values are the difference in means $[95 \% \mathrm{Cl}]$ when compared with the $\varepsilon 3 \mathrm{~A}$ reference haplotype (mean $[95 \% \mathrm{Cl}]=1.33[1.29-1.37] \mathrm{mmol} / \mathrm{L}$ ) using Thesias software. 
the reference $\varepsilon 3 \mathrm{~A}$ haplotype $(\Delta[95 \% \mathrm{CI}]=-0.05[-0.27-$ -0.17] $\mathrm{mmol} / \mathrm{L}, p=0.81)$. Hence, the $\mathrm{G}$ allele of the rs4420638 SNP may have counterbalanced the deleterious effect of the $\varepsilon 4$ allele.

Similar haplotype results were obtained for plasma total cholesterol levels (data not shown).

\section{Discussion}

The importance of APOE in lipid and lipoprotein metabolism is well established. However the impact of $A P O E$ polymorphisms has never been investigated in an Algerian population. So in this study, we assessed the relationship between three APOE polymorphisms (epsilon, rs439401 and rs4420638) and metabolic trait variations in a population from Oran, Algeria, the ISOR study. To the best of our knowledge, this was the first study to characterize associations of the three above-mentioned $A P O E$ gene polymorphisms with anthropometric, biochemical and clinical parameters in an Algerian population.

The frequency of the $\varepsilon 4$ allele in Europe parallels the incidence of CHD and other diseases [11,30,31]. It follows a north-to-south gradient and ranges from more than 0.22 in Finland and Greenland [32-34] to less than 0.07 in Greece and Italy [35-37]. In our study, the $\varepsilon 4$ allele frequency (0.10) was similar to values observed in other North African populations (around 0.10 in Moroccan populations [26,38] and around 0.08 in Tunisian populations $[27,28])$.

The minor allele frequency of the rs439401 SNP (located within the $A P O E / A P O C 1$ cluster) was 0.38 in the ISOR study. Similar frequencies have been reported in the literature and range from 0.33 to $0.36[14,39]$.

For the rs4420638 SNP (situated lying 14 kb downstream of the $A P O E$ locus in the adjacent $A P O C 1$ gene), the minor allele frequency (0.11) was markedly lower than the value observed in European samples $[14,24,40]$.

In the ISOR study, the $\varepsilon 2$ allele was not significantly associated with plasma lipid variations $(0.06 \leq p \leq 0.18)$. This is probably due to too few of $\varepsilon 2$ carriers $(n=67)$. Only the $\varepsilon 4$ allele showed an association with higher levels of total cholesterol and LDL-cholesterol. Furthermore, the $\varepsilon 4$ allele was associated with higher concentrations of triglycerides, as previously observed by Kofler et al. in a study performed in the United Kingdom [41]. The APOE \&4 isoform (which binds preferentially to VLDLs) can interfere with plasma lipase activity or with the triglyceride removal system; this results in delayed lipolysis or clearance of plasma triglycerides in subjects bearing the $\varepsilon 4 / \varepsilon 3$ phenotype [18]. Therefore, our results are consistent with previous studies [42-45]. In contrast with previous studies in multi-ethnic populations [41,46-48] but consistently with other studies in Tunisian subjects $[27,28]$, we did not detect significant associations between the $A P O E$ epsilon polymorphism and HDL-cholesterol levels in the ISOR sample. Other studies conducted in Arab population samples are therefore needed to conclude.

Despite the deleterious effect of the $\varepsilon 4$ allele on lipid parameters observed in the ISOR study, the lipid concentrations did not reach abnormal threshold values. A case-control study on the risk of myocardial infarction conducted in Oran in 2001 also showed that plasma concentrations of all lipid parameters were systematically lower in Algerian subjects than in Irish and French individuals [49].

We found significant association between the rs439401 SNP and triglyceride concentrations. This association has previously been observed in European GWAS of blood lipid levels $[14,22]$. However, this association disappeared after further adjustment for the APOE epsilon polymorphism, suggesting that the effect of rs439401 was overshadowed by the epsilon polymorphism.

In the ISOR study, the rs4420638 SNP was not significantly associated with any metabolic traits, contrary to what has been previously described [50]. These discrepancies could be explained by differences in the LD structure between rs4420638 and the APOE epsilon polymorphism in the Algerian and European populations $\left(\mathrm{D}^{\prime}=0\right.$ and +16 with rs7412 and rs429358, respectively in the ISOR study versus $D^{\prime}=+66$ and -69 with rs7412 and rs429358, respectively in the EUR panel of the 1000 Genomes database (December 2012 release, http://browser.1000genomes. org)). Therefore the effect of the rs4420638 SNP could be mainly due to the epsilon polymorphism in European samples but be independent in the ISOR study. This result should be investigated in other North-African populations.

Haplotype analysis was performed to better understand the information provided by the individual SNP analysis. This analysis showed that regarding plasma LDL-cholesterol (or total cholesterol) levels, the rs4420638 polymorphism could counterbalance the deleterious effect of the epsilon 4 allele.

\section{Conclusion}

We showed that the impact of the APOE $\varepsilon 4$ allele on the plasma lipid profile is similar in an Algerian population to what is known in other countries. It is noteworthy that the rs $4420638 \mathrm{G}$ allele could counterbalance the deleterious effect of the $A P O E \& 4$ allele on LDL-cholesterol levels in a North African population. Replications in larger studies are required.

\section{Methods}

\section{Subjects}

\section{The ISOR (InSulino-résistance à ORan) study}

The ISOR study was performed between 2007 and 2009 . The study's objectives and procedures were approved by the independent ethics committee at the Algerian National 
Agency for the Development of Health Research. The ISOR study was a population-based, cross-sectional study of a representative sample of 787 subjects (378 men and 409 women, aged between 30 and 64) recruited within the city of Oran. Subjects were selected at random from social security rolls. All subjects consented freely to participation in the study. A questionnaire on lifestyle (physical activity, tobacco use and alcohol intake), personal and family medical histories, current medication and socioeconomic and educational levels was completed during a face-to-face interview. Anthropometric data were also recorded.

The level of physical activity was defined in quartiles as "none", "low", "medium" and "high" after summing exercise scores for sporting activities, walking, housework and physical activity at work.

In terms of tobacco use, participants were categorized as either smokers (i.e. individuals reporting at least one cigarette per day) or non-smokers. In the study questionnaire, subjects were asked to report their weekly consumption of wine, beer, and spirits. As there were very few drinkers $(n=25,3.2 \%)$, this variable was not taken into account in the final analysis.

The anthropometric measurements included height, body weight, waist circumference and hip circumference. Height and weight were measured while the subject was barefoot and lightly dressed. The BMI was calculated according to the Quetelet equation. Systolic and diastolic blood pressure values (SBP and DBP, respectively) were measured on the right arm with the subject in the sitting position, using a standard mercury sphygmomanometer. Measurements were made before and after completion of the questionnaire, with an interval of at least $10 \mathrm{mi}$ nutes. The mean value of the blood pressure readings was considered in the final analysis.

After a 12 h overnight fast, two $15 \mathrm{ml}$ blood samples were collected for each subject (in a disodium EDTA tube for subsequent DNA analysis and in a heparin tube for clinical chemistry tests).

A multichannel analyzer and dedicated kits (Humastar ${ }^{\oplus}$, HUMAN Diagnostics, Wiesbaden, Germany) were used for the colorimetric, enzymatic measurement of cholesterol (kit: monotest cholesterol with cholesterol esterase, cholesterol oxidase and peroxidase), triglycerides (kit: peridochrom triglyceride with glycerol phosphate oxidase and peroxidase) and glucose (kit: glucose, glucose oxidase and peroxidase). Plasma LDL-cholesterol levels were calculated according to the Friedwald equation. High-density lipoprotein cholesterol levels were measured after sodium phosphotungstate/magnesium chloride precipitation of chylomicrons and VLDL and LDL-cholesterol and then centrifugation. Plasma insulin levels were measured in a microparticle enzyme immune assay running on an AxSYM analyzer (Abbott Laboratories, Abbott Park, Illinois, USA).
Genomic DNA was extracted from white blood cells by using the Stratagene ${ }^{\bullet}$ kit (Agilent Technologies, Les Ulis, France), according to the manufacturer's protocol.

\section{Genotyping}

The APOE SNPs (rs429358, rs7412, rs439401 and rs4420638) were genotyped using KASPar technology (KBioscience, Hoddesdon, UK) with the following probes: rs429358: [GACATGGAGGACGTG[C/T]GCGGCCGCC TGGTGC], rs7412: [GATGACCTGCAGAAG[C/T]GCC TGGCAGTGTACC], rs439401: [GCCGGCACTCTCTTC [C/T]CCTCCCACCCCCTCA], rs4420638: [TGCTACAC TTTTCCT[A/G]GTGTGGTCTACCCGA]. The genotyping success rates ranged from $93 \%$ to $96 \%$.

\section{Statistical analyses}

Statistical analyses were performed with SAS 9.1 software (SAS Institute Inc., Cary, NC, USA). The HardyWeinberg equilibrium was tested using a $X^{2}$ test with one degree of freedom (d.f.).

Intergroup comparisons of means were performed with (i) a general linear model comparing $\varepsilon 2$ carriers ( $\varepsilon 2 \varepsilon 2$ and $\varepsilon 2 \varepsilon 3$ subjects) or $\varepsilon 4$ carriers ( $\varepsilon 4 \varepsilon 4$ and $\varepsilon 4 \varepsilon 3$ subjects) with $\varepsilon 3$ carriers ( $\varepsilon 3 \varepsilon 3$ homozygotes) for the $A P O E$ epsilon polymorphism and (ii) an additive model for the rs439401 and rs4420638 polymorphisms. Subjects with the $\varepsilon 2 \varepsilon 4$ genotype $(n=3)$ were excluded from the analyses because of the possible opposing biological effects of the $\varepsilon 2$ and $\varepsilon 4$ alleles.

Data on triglycerides, glucose and insulin levels were log-transformed to obtain normal distributions. Estimated means were subsequently back-transformed for presentation in the tables.

For anthropometric variables, the confounding variables were age, gender, smoking status and physical activity. For biological and biochemical variables, the confounding variables were age, gender, BMI, smoking status and physical activity. For the rs439401 and rs4420638 polymorphisms, data were further adjusted for the $A P O E$ epsilon polymorphism coded in three genotypes as follows: $\varepsilon 2$ carriers ( $\varepsilon 2 \varepsilon 2$ and $\varepsilon 2 \varepsilon 3$ subjects); $\varepsilon 4$ carriers ( $\varepsilon 4 \varepsilon 4$ and $\varepsilon 4 \varepsilon 3$ subjects) and $\varepsilon 3$ carriers ( $\varepsilon 3 \varepsilon 3$ subjects).

After Bonferroni correction, only associations with an uncorrected $p$ value below 0.017 were considered to be statistically significant (i.e. 0.05 divided by the number of polymorphisms considered).

General linear models were used to investigate potential interactions by adding an interaction ((gender or BMI) x polymorphism) term.

Linkage disequilibrium figure and values were calculated with Haploview 4.2 (http://www.broadinstitute. org/scientific-community/science/programs/medical-andpopulation-genetics/haploview/haploview). 
Haplotype frequencies derived from all studied polymorphisms were estimated independently of phenotype. A two-step haplotype analysis was performed. Firstly, in order to reduce the haplotype dimension and select the most informative, parsimonious haplotype configuration for the prediction of phenotypic variability, we applied the maximum likelihood model to all the possible 1 to $k$-loci combinations of polymorphisms that could be derived from the 4. APOE SNPs with the GridHaplo software [51]. Akaike's information criterion (AIC) was calculated for each model (including a model with no polymorphisms) [52]. All AIC values were rescaled by subtracting the smallest AIC value obtained for the whole set of models. According to a rule derived by extensive Monte Carlo simulation, all models with a rescaled AIC $\leq 2$ can be considered to be "equivalent" to the model with the lowest min AIC. The most parsimonious of the latter (corresponding to the minimal haplotype configuration) was selected. Secondly, haplotype analyses were performed using the Thesias software package (http:// ecgene.net/genecanvas) [29]. Haplotype analyses were adjusted for age, gender, BMI, smoking status and physical activity level.

\begin{abstract}
Abbreviations
AIC: Akaike's information criterion; APOE: Apolipoprotein E; BMI: Body mass index; CHD: Coronary heart disease; DBP: Diastolic blood pressure; DNA: Deoxyribonucleic acid; d.f: Degree of freedom; GWAS: Genome-wide association studies; HDL: High-density lipoprotein; ISOR: InSulino-résistance à ORan; LD: Linkage disequilibrium; LDL: Low-density lipoprotein; SBP: Systolic blood pressure; SNP: Single nucleotide polymorphism; VLDL: Very lowdensity lipoprotein.
\end{abstract}

\section{Competing interests}

The authors declare that they have no competing interests.

\section{Authors' contributions}

SMB, LH, NSM, PA, AM and LG designed research; SMB, LH, IMH, AM and LG conducted research; HOD, SLH, IMH, SMB and LH participated in the recruitment of subjects; $L G$ built the database with the support of $B G B ; X H$, $D N M$ and $H B$ performed the DNA extraction under the supervision of $L G$; $H B$ and LG performed the statistical analyses; $H B, S M B, A M$ and $L G$ interpreted the results. IMH assayed biochemical parameters; HB wrote the paper under the supervision of SMB, AM and LG; HB, SMB, AM and LG had primary responsibility for final content. All authors read and approved the final manuscript.

\section{Acknowledgements}

The ISOR project was funded through a collaboration agreement between the Direction de la Post-Graduation et de la Recherche-Formation (DPGRF) (Algeria) and the Institut National de la Santé et de la Recherche Médicale (INSERM) (France). The work in France was also part-funded by INSERM. The work in Algeria was also part-funded by the Algerian National Agency for the Development of Health Research (ANDRS) and a grant from the Projets Nationaux de Recherche (PNR) program run by the Algerian Direction Générale de la Recherche Scientifique et du Développement Technologique/ Ministère de l'Enseignement Supérieur et de la Recherche Scientifique (DGRSDT/MESRS).

\section{Author details}

'Laboratoire de Génétique Moléculaire et Cellulaire, Université des Sciences et de Technologie d'Oran Mohamed Boudiaf, Oran, Algeria. ${ }^{2}$ Département de Biotechnologie, Faculté des Sciences de la Nature et de la Vie, Université d'Oran, Oran, Algeria. ${ }^{3}$ INSERM, U744; Institut Pasteur de Lille, Université Lille
Nord de France, Lille, France. ${ }^{4}$ Caisse Nationale des Assurances Sociales des travailleurs salariés, Clinique Spécialisée en Orthopédie et Rééducation des Victimes des Accidents de Travail, Oran, Algeria. ${ }^{5}$ Faculté de Médecine, Université Djillali Liabes de Sidi Bel Abbes, Sidi Bel Abbes, Algeria.

${ }^{6}$ LABoratoire des Systèmes d'Information en Santé, Université d'Oran, Oran, Algeria.

Received: 27 August 2013 Accepted: 21 October 2013

Published: 25 October 2013

\section{References}

1. Davignon J, Gregg RE, Sing CF: Apolipoprotein E polymorphism and atherosclerosis. Arteriosclerosis 1988, 8:1-21.

2. Eichner JE, Dunn ST, Perveen G, Thompson DM, Stewart KE, Stroehla BC: Apolipoprotein E polymorphism and cardiovascular disease: a HuGE review. Am J Epidemiol 2002, 155:487-495.

3. Institut National de Santé Publique: Transition épidémiologique et système de santé. Synthèse de l'enquête morbidité. Alger: INSP Ed: Projet TAHINA; 2002.

4. Mackay JMG: The Atlas of Heart Disease and Stroke. Geneva: World Health Organization; 2004

5. World Health Organization (WHO): The World Health Report 2008. 2013. Available from: URL: http://www.who.int/whr/2008/whr08_en.pdf.

6. Murray CJ, Lopez AD: Alternative projections of mortality and disability by cause 1990-2020: Global Burden of Disease Study. Lancet 1997, 349:1498-1504.

7. Watkins H, Farrall M: Genetic susceptibility to coronary artery disease: from promise to progress. Nat Rev Genet 2006, 7:163-173.

8. Ginsberg HN, Kris-Etherton P, Dennis B, Elmer PJ, Ershow A, Lefevre M, Pearson T, Roheim P, Ramakrishnan R, Reed R, et al: Effects of reducing dietary saturated fatty acids on plasma lipids and lipoproteins in healthy subjects: the DELTA Study, protocol 1. Arterioscler Thromb Vasc Biol 1998, 18:441-449.

9. Savolainen MJ, Kesaniemi YA: Effects of alcohol on lipoproteins in relation to coronary heart disease. Curr Opin Lipidol 1995, 6:243-250.

10. Gielen $\mathrm{S}$, Schuler $\mathrm{G}$, Hambrecht R: Exercise training in coronary artery disease and coronary vasomotion. Circulation 2001, 103:E1-E6.

11. Wilson PW, Schaefer EJ, Larson MG, Ordovas JM: Apolipoprotein E alleles and risk of coronary disease. A meta-analysis. Arterioscler Thromb Vasc Biol 1996, 16:1250-1255.

12. Song Y, Stampfer MJ, Liu S: Meta-analysis: apolipoprotein E genotypes and risk for coronary heart disease. Ann Intern Med 2004, 141:137-147.

13. Bennet AM, Di Angelantonio E, Ye Z, Wensley F, Dahlin A, Ahlbom A, Keavney B, Collins R, Wiman B, de Faire U, et al: Association of apolipoprotein $\mathrm{E}$ genotypes with lipid levels and coronary risk. JAMA 2007, 298:1300-1311.

14. Teslovich TM, Musunuru K, Smith AV, Edmondson AC, Stylianou IM, Koseki M, Pirruccello JP, Ripatti S, Chasman DI, Willer CJ, et al: Biological, clinical and population relevance of 95 loci for blood lipids. Nature 2010, 466:707-713.

15. Anoop S, Misra A, Meena K, Luthra K: Apolipoprotein E polymorphism in cerebrovascular \& coronary heart diseases. Indian J Med Res 2010, 132:363-378.

16. Das HK, McPherson J, Bruns GA, Karathanasis SK, Breslow JL: Isolation, characterization, and mapping to chromosome 19 of the human apolipoprotein E gene. J Biol Chem 1985, 260:6240-6247.

17. Siest G, Pillot T, Regis-Bailly A, Leininger-Muller B, Steinmetz J, Galteau MM, Visvikis S: Apolipoprotein $\mathrm{E}$ : an important gene and protein to follow in laboratory medicine. Clin Chem 1995, 41:1068-1086.

18. Dallongeville J, Lussier-Cacan S, Davignon J: Modulation of plasma triglyceride levels by apoE phenotype: a meta-analysis. J Lipid Res 1992, 33:447-454.

19. Wilson PW, Myers RH, Larson MG, Ordovas JM, Wolf PA, Schaefer EJ: Apolipoprotein $\mathrm{E}$ alleles, dyslipidemia, and coronary heart disease. The Framingham Offspring Study. JAMA 1994, 272:1666-1671.

20. Costanza MC, Beer-Borst S, James RW, Gaspoz JM, Morabia A: Consistency between cross-sectional and longitudinal SNP: blood lipid associations. Eur J Epidemiol 2012, 27:131-138.

21. Petkeviciene J, Smalinskiene A, Luksiene DI, Jureniene K, Ramazauskiene V, Klumbiene J, Lesauskaite V: Associations between apolipoprotein E genotype, diet, body mass index, and serum lipids in Lithuanian adult population. PLoS One 2012, 7:e41525. 
22. Aulchenko YS, Ripatti S, Lindqvist I, Boomsma D, Heid IM, Pramstaller PP, Penninx BW, Janssens AC, Wilson JF, Spector T, et al: Loci influencing lipid levels and coronary heart disease risk in 16 European population cohorts. Nat Genet 2009, 41:47-55.

23. Kathiresan S, Melander O, Guiducci C, Surti A, Burtt NP, Rieder MJ, Cooper GM, Roos C, Voight BF, Havulinna AS, et al: Six new loci associated with blood low-density lipoprotein cholesterol, high-density lipoprotein cholesterol or triglycerides in humans. Nat Genet 2008, 40:189-197.

24. Willer CJ, Speliotes EK, Loos RJ, Li S, Lindgren CM, Heid IM, Berndt SI, Elliott AL, Jackson AU, Lamina C, et al: Six new loci associated with body mass index highlight a neuronal influence on body weight regulation. Nat Genet 2009, 41:25-34.

25. Liu Y, Zhou D, Zhang Z, Song Y, Zhang D, Zhao T, Chen Z, Sun Y, Zhang D, Yang $Y$, et al: Effects of genetic variants on lipid parameters and dyslipidemia in a Chinese population. J Lipid Res 2011, 52:354-360

26. Lahlali-Kacemi N, Bamou Y, Guedira A, Hassani M, Visvikis S, Siest G, Alami N, Kabbaj O, Lahrichi M: Apolipoprotein E polymorphism in a Moroccan population: allele frequency and relation to plasma lipid concentrations. Ann Biol Clin (Paris) 2002, 60:73-78.

27. Jemaa R, Elasmi M, Naouali C, Feki M, Kallel A, Souissi M, Sanhaji H, Hadj TS, Souheil O, Kaabachi N: Apolipoprotein E polymorphism in the Tunisian population: frequency and effect on lipid parameters. Clin Biochem 2006, 39:816-820

28. Bahri R, Esteban E, Moral P, Hassine M, Ben Hamda K, Chaabani H: Apolipoprotein gene polymorphisms and plasma levels in healthy Tunisians and patients with coronary artery disease. Lipids Health Dis 2008, 7:46.

29. Tregouet DA, Garelle V: A new JAVA interface implementation of THESIAS: testing haplotype effects in association studies. Bioinformatics 2007, 23:1038-1039.

30. Schiele F, De Bacquer D, Vincent-Viry M, Beisiegel U, Ehnholm C, Evans A, Kafatos A, Martins MC, Sans S, Sass C, et al: Apolipoprotein E serum concentration and polymorphism in six European countries: the ApoEurope Project. Atherosclerosis 2000, 152:475-488.

31. Kosunen O, Talasniemi S, Lehtovirta M, Heinonen O, Helisalmi S, Mannermaa A, Paljarvi L, Ryynanen M, Riekkinen PJ Sr, Soininen H: Relation of coronary atherosclerosis and apolipoprotein E genotypes in Alzheimer patients. Stroke 1995, 26:743-748.

32. Gerdes LU: The common polymorphism of apolipoprotein E: geographical aspects and new pathophysiological relations. Clin Chem Lab Med 2003, 41:628-631.

33. Ehnholm C, Lukka M, Kuusi T, Nikkila E, Utermann G: Apolipoprotein E polymorphism in the Finnish population: gene frequencies and relation to lipoprotein concentrations. J Lipid Res 1986, 27:227-235

34. de Knijff $P$, Johansen LG, Rosseneu M, Frants RR, Jespersen J, Havekes LM: Lipoprotein profile of a Greenland Inuit population. Influence of anthropometric variables, Apo E and A4 polymorphism, and lifestyle. Arterioscler Thromb 1992, 12:1371-1379.

35. Sklavounou E, Economou-Petersen E, Karadima G, Panas M, Avramopoulos D, Varsou A, Vassilopoulos D, Petersen MB: Apolipoprotein E polymorphism in the Greek population. Clin Genet 1997, 52:216-218.

36. Deiana L, Pes GM, Carru C, Errigo A, Pettinato S, Carcassi C, Baggio G, Contu L: Lack of influence of apolipoprotein E4 on lipoprotein levels in the island population of Sardinia. Eur J Clin Invest 1998, 28:290-294.

37. Barbagallo CM, Polizzi F, Severino M, Rizzo M, Vivona N, Onorato F, Caldarella R, Cefalu AB, Noto D, Notarbartolo A, et al: ApoE polymorphism in a small Mediterranean island: relationships with plasma lipids, lipoproteins and LDL particle size. Eur J Epidemio/ 2001, 17:707-713.

38. Valveny N, Esteban E, Kandil M, Moral P: APO E polymorphism in Spanish and Moroccan populations. Clin Genet 1997, 51:354-356.

39. Kring SI, Brummett BH, Barefoot J, Garrett ME, Ashley-Koch AE, Boyle SH, Siegler IC, Sorensen TI, Williams RB: Impact of psychological stress on the associations between apolipoprotein $\mathrm{E}$ variants and metabolic traits: findings in an American sample of caregivers and controls. Psychosom Med 2010, 72:427-433.

40. Barber MJ, Mangravite LM, Hyde CL, Chasman DI, Smith JD, McCarty CA, Li X Wilke RA, Rieder MJ, Williams PT, et al: Genome-wide association of lipidlowering response to statins in combined study populations. PLOS One 2010, 5:e9763.

41. Kofler BM, Miles EA, Curtis P, Armah CK, Tricon S, Grew J, Napper FL, Farrell L, Lietz G, Packard CJ, et al: Apolipoprotein E genotype and the cardiovascular disease risk phenotype: impact of sex and adiposity (the FINGEN study) Atherosclerosis 2012, 221:467-470.

42. Hallman DM, Boerwinkle E, Saha N, Sandholzer C, Menzel HJ, Csazar A, Utermann G: The apolipoprotein E polymorphism: a comparison of allele frequencies and effects in nine populations. Am J Hum Genet 1991, 49:338-349.

43. Xhignesse M, Lussier-Cacan S, Sing CF, Kessling AM, Davignon J: Influences of common variants of apolipoprotein $E$ on measures of lipid metabolism in a sample selected for health. Arterioscler Thromb 1991, 11:1100-1110.

44. Howard BV, Gidding SS, Liu K: Association of apolipoprotein E phenotype with plasma lipoproteins in African-American and white young adults. The CARDIA Study. Coronary Artery Risk Development in Young Adults. Am J Epidemiol 1998, 148:859-868.

45. Wilson HM, Patel JC, Russell D, Skinner ER: Alterations in the concentration of an apolipoprotein E-containing subfraction of plasma high density lipoprotein in coronary heart disease. Clin Chim Acta 1993, 220:175-187.

46. Alvim RO, Freitas SR, Ferreira NE, Santos PC, Cunha RS, Mill JG, Krieger JE, Pereira AC: APOE polymorphism is associated with lipid profile, but not with arterial stiffness in the general population. Lipids Health Dis 2010, 9:128.

47. Medina-Urrutia AX, Cardoso-Saldana GC, Zamora-Gonzalez J, Liria YK, Posadas-Romero C: Apolipoprotein E polymorphism is related to plasma lipids and apolipoproteins in Mexican adolescents. Hum Biol 2004, 76:605-614

48. Liang S, Steffen LM, Steffen BT, Guan W, Weir NL, Rich SS, Manichaikul A Vargas JD, Tsai MY: APOE genotype modifies the association between plasma omega-3 fatty acids and plasma lipids in the Multi-Ethnic Study of Atherosclerosis (MESA). Atherosclerosis 2013, 228:181-187.

49. Mediene-Benchekor S, Brousseau T, Richard F, Benhamamouch S, Amouyel P: Blood lipid concentrations and risk of myocardial infarction. Lancet 2001 358:1064-1065.

50. Pendergrass SA, Brown-Gentry K, Dudek S, Frase A, Torstenson ES, Goodloe R, Ambite JL, Avery CL, Buyske S, Buzkova P, et al: Phenome-Wide Association Study (PheWAS) for Detection of Pleiotropy within the Population Architecture using Genomics and Epidemiology (PAGE) Network. PLoS Genet 2013, 9:e1003087.

51. Tregouet DA, Konig IR, Erdmann J, Munteanu A, Braund PS, Hall AS, Grosshennig A, Linsel-Nitschke P, Perret C, DeSuremain M, et al: Genomewide haplotype association study identifies the SLC22A3-LPAL2-LPA gene cluster as a risk locus for coronary artery disease. Nat Genet 2009, 41:283-285.

52. Akaike $\mathrm{H}$ : A new look at the statistical model identification. IEEE Transactions on Automated Control AC 1974, 19:716-723.

doi:10.1186/1476-511X-12-155

Cite this article as: Boulenouar et al.: Impact of $A P O E$ gene

polymorphisms on the lipid profile in an Algerian population. Lipids in Health and Disease 2013 12:155.

\section{Submit your next manuscript to BioMed Central and take full advantage of:}

- Convenient online submission

- Thorough peer review

- No space constraints or color figure charges

- Immediate publication on acceptance

- Inclusion in PubMed, CAS, Scopus and Google Scholar

- Research which is freely available for redistribution 